A paper presented at the 29th Annual Convention of the American Institute of Elecirical Engineers, Boston, Mass., June 28, 1912.

Copyright, 1912. By A.I.E.E.

\title{
THE RUNAWAY SPEED OF WATERWHEELS AND ITS EFFECT ON CONNECTED ROTARY MACHINERY
}

BY DANIEL W. MEAD

In the selection of hydroelectric units, the operating speed of the turbines should be so chosen as to give the most efficient results under the varying conditions of operation. When the head of water is constant, the choice, unless modified somewhat by the necessary synchronous speed of the generator, should ordinarily be the speed at which the turbine will operate with the highest efficiency with the normal condition of load.

Under operating conditions the normal speed of the turbine is usually maintained, as the load varies, by the action of the turbine governor which opens or closes the gate or gates by which the water is supplied to the turbines, as the load on the connected generator, and consequently, on the waterwheel, increases or decreases. If the changes in load take place without a corresponding change in the quantity of water admitted to the wheels, the speed will necessarily vary, increasing as the load decreases, and decreasing with an increase in load. Under the condition of maximum load, with the turbine gate at or near maximum opening, a sudden dropping off of the load without a corresponding change in gate opening will give rise to a considerable increase in speed, which has in some cases resulted in disaster to the connected generators, when such generators had not been designed for the overspeed to which they were subjected. Such accidents have usually been due to the breaking or sticking of the governor or its connections, whereby the control normally exerted by the governor on the gate opening has been accidentally discontinued, allowing the turbine, as the load dropped, to 
speed up and run away. Such conditions, while not common, may happen in any hydraulic turbine installation, and to assure safety under such runaway conditions the generator or other rotary machinery connected with the turbine must be so designed that it will operate with safety at such runaway speed as is likely to occur.

At present it is current practise to design the generators for a possible 100 per cent overspeed in order to assure safety under such conditions. Such a basis for design often involves a large extra expense in generator construction, on account of the necessary extra strength of the rotor, and an inquiry as to the safe allowance for overspeed which should be made under varying conditions of operation and installation should, therefore, be of interest and importance in securing the necessary safety of the installation, combined with maximum economy in construction consistent with such safety.

\section{NOMENClature}

The following symbols will be used in the discussion that follows

$D D_{a}=$ diameter of homologous wheels or wheels of same type.

$E \quad=$ energy.

$\boldsymbol{e} \quad=$ subscript $e$ attached to any coefficient shows that the value of the coefficient as expressed is for the conditions of maximum efficiency of the wheel.

$F \quad=$ force.

$g \quad=$ acceleration of gravity 32.16 .

$h h_{a} \quad=$ head under which wheels are to operate.

$h_{1} \quad=$ head of one foot.

$l=$ length of brake arm or leverage of resistance.

$n n_{a} \quad=$ rev. per min. of wheels of diameter $D$ and $D_{a}$ under same head; also rev. per min. of wheel of same diameter under heads of $h$ and $h_{a}$.

$n_{1} \quad=$ rev. per min. under one-foot head.

$P P_{a}=$ power of wheels of diameter $D$ and $D_{a}$ under same head; also the power of the wheel of same diameter under head $h$ and $h_{a}$.

$P_{1} \quad=$ power of wheel under one-foot head.

$S \quad=$ space passed through.

$v \quad=$ velocity of water due to head.

$v_{a} \quad=$ average velocity. 


$$
\begin{aligned}
& v^{\prime} \quad=\text { velocity of circumference or periphery of impeller } \\
& \text { which may be measured on any fixed diameter. } \\
& v_{r} \quad=\text { resultant velocity. } \\
& W \quad=\text { weight } \text { or resistance applied. } \\
& w \quad=\text { unit weight of water (per cubic foot). } \\
& \pi \quad=3.14159=\text { ratio of circumference to diameter of the }
\end{aligned}
$$

Some Elementary Principles of Turbine Governing

The writer has already pointed out in another place* that the power delivered by any waterwheel may be expressed in terms of resistance overcome by the wheel in a known distance and in a known time by the formula

$$
P=\frac{2 \pi l W}{33000} \times n
$$

In this formula, $P=$ power,

$$
\begin{aligned}
\frac{2 \pi l W}{33000} & =\text { resistance overcome per revolution, and } \\
n & =\text { the number of revolutions per minute. }
\end{aligned}
$$

The actual variations of resistance and speed under certain conditions are shown in the upper curve of Fig. 1, and the resulting variations in power under various speeds are shown by the lower curve of the same figure. The conditions illustrated in Fig. 1 are not applicable to normal operating conditions of a

*See "Water Power Engineering," p. 440. 
hydroelectric installation, which require constant speed, but the conditions illustrated do apply to the accidental conditions above outlined and to the actual working conditions of a pump driven by an hydraulic turbine, where the pressure in the delivery pipes from the pump is allowed to vary somewhat. The upper curve line $A X B$ illustrates the actual and varying relations of resistance to speed in a turbine operating at a fixed gate opening. The point $A$ shows the condition under which the resistance is so great that the turbine is held stationary with the

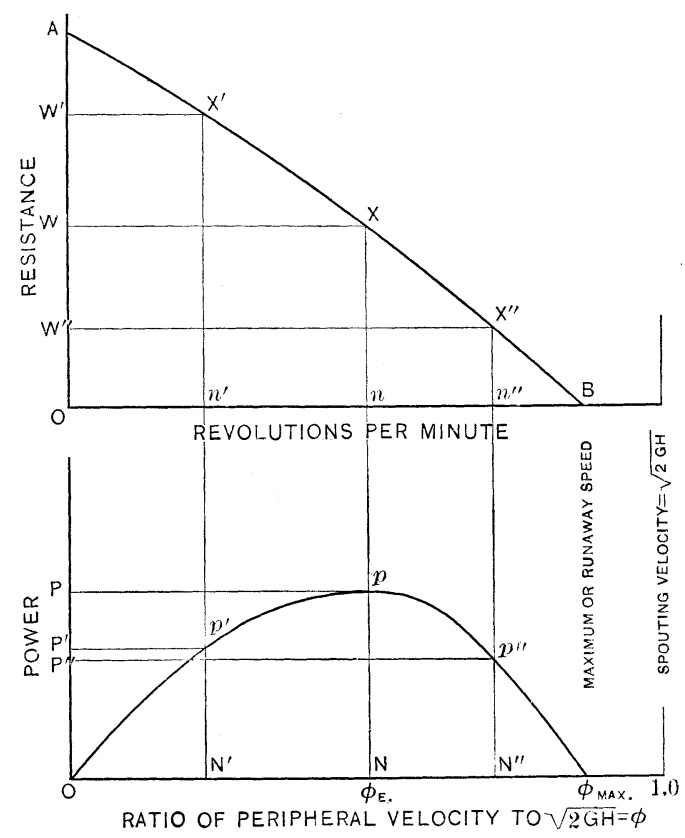

Fig. 1

result of no power output (see lower curve). The point $X$ shows the condition where the relation of resistance to speed is such as to result in a maximum power output of the turbine under the gate conditions considered. The point $B$ shows the conditions under which the exterior resistance is completely removed and the entire energy of the water, as far as utilized at all, is expended in overcoming the wheel friction, resulting in maximum speed and zero power output.

A turbine-driven pumping plant with variable pressure in the discharge pipe system will give self-regulation as indicated in 
Fig. 1. In such case the point $A$ represents a pressure in the system so great as to result in the stopping of the pump, and hence no speed and no pump discharges. Point $X$ represents moderate pressure and normal discharge for which the system is designed, while point $B$ represents the entire removal of pressure and the pump discharging its maximum under the gate condition. In practise, the actual variation extends to a limited extent, only, on each side of point $X$ and a radical change in discharge of pressure under satisfactory working conditions must be accompanied by a change in the gate opening.
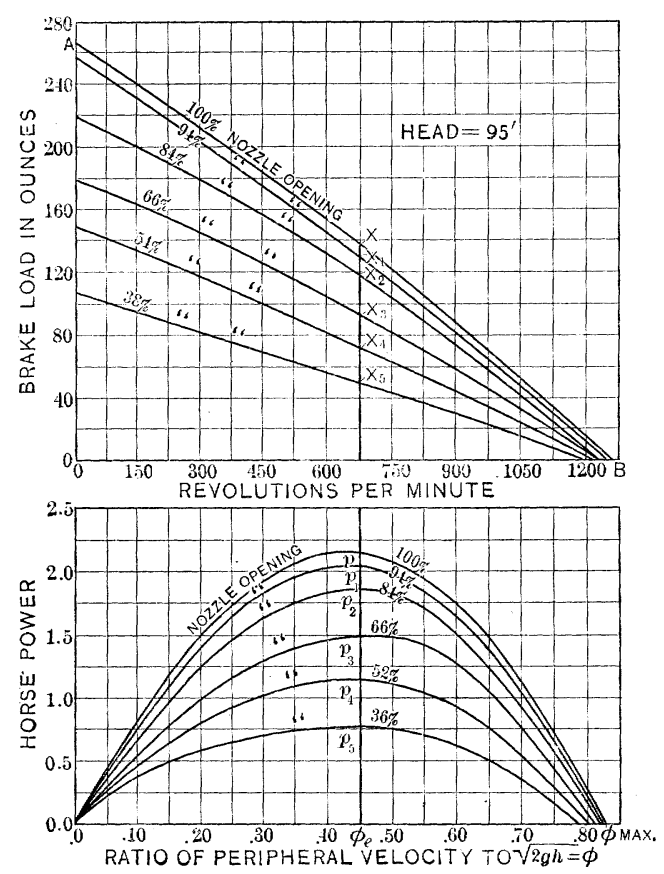

FIG. 2

Fig. 2, constructed from experimental data*, illustrates the results which must obtain for the satisfactory regulation of a constant-speed hydraulic unit, and consequently, of a hydroelectric unit. Here again the upper curves show the actual relations of resistance to speed at various gate openings, while the lower curves show the relations of power to speed at the same

* See Figs. 15 and 16, Bulletin 337, University of Wisconsin. "The Relation of Experimental Results to the Theory of the Tangential Wheel." 
gate openings shown by the upper curves. In the lower curves the speed factor is expressed as a ratio $\phi$ between the peripheral velocity of the wheel and the spouting velocity of water. Under such conditions satisfactory operation will be represented by the line $X X_{1} p p_{1} \phi_{e}$. The point $X$ and the corresponding point $p$ (on the line of 100 per cent nozzle opening of both upper and lower curves) represent the conditions of maximum gate opening, and consequently of maximum power. If the wheel is improperly selected for the load to be carried, and the power demands exceed this limit, a slowing down in speed will result as illustrated in the discussion of Fig. 1, and under such conditions the service will be satisfactory. If, however, the power varies only between the maximum and zero, satisfactory regulation must be accomplished by a proper change in the nozzle opening as the load varies, the point of operation dropping from position $p$ to $p_{1}, p_{2}, p_{3}$, etc., as the power demands decrease, or rising from $p_{5}$ to the higher position as the power demands increase. This result is accomplished in practise by a turbine governor, the details of the operation of which are immaterial for this discussion. Now, if at any point of the load the governor becomes disconnected and the load suddenly varies, the gates may either remain fixed or swing to a fixed position, and a variation in speed will result similar to that illustrated in Fig. 1, or by any one of the upper curves of Fig. 2 which corresponds to the fixed gate opening. If the load is entirely removed a runaway speed will result, which may vary according to the fixed gate condition under which this accident occurs.

Fig. 2 illustrates the experimental results from a 12 -in. tangential wheel under a 95 -foot head, operating under a load applied by a prony brake. It will be noted that the operating condition is taken at 675 revolutions per minute, or with $\phi_{e}=45$ (that is, with the periphery of the wheel moving with a velocity 45 per cent of the spouting velocity of the water under a 95 -foot head).

In this case, at the maximum or runaway speed $\phi$ did not exceed $\phi_{\max }=80$ for 36 per cent gate opening, or $\phi_{\max .}=84$ for 100 per cent gate opening, and if a generator had been connected to this wheel these speeds would have been slightly reduced by the amount of power necessary to operate the unloaded generator. In this case it is evident that the runaway speed of the wheel would be 186.5 per cent of the normal speed at full gate and 177.5 per cent of the normal speed at 36 per 
cent gate, without considering other than the actual wheel friction.

\section{The Hydraulics of Runaway Speed}

In order to present this subject clearly, it is necessary to consider, briefly at least, the hydraulics of the turbine as it affects this problem. A jet of water spouting from the nozzle of a wheel will acquire a velocity $v$ due to the head $h$ represented in the formula

$$
v=\sqrt{2 g h}
$$

and will possess energy in foot-pounds per second $E$ due to velocity $v$ and weight of water discharged per second, $W=q w$, as follows -

$$
E=\frac{W v^{2}}{2 g}=\frac{q w v^{2}}{2 g}
$$

The energy of the jet leaving the orifice is the product of a force $F$, which, acting on the weight of water $q w$ for one second, gives it the velocity $v$.

The space passed through by the force in one second in raising the velocity from 0 to $v$ is

$$
S=v_{a} t=\frac{v}{2}
$$

and therefore the work is

$$
F S=\frac{F v}{2}
$$

which is also an expression for the energy of the jet. Therefore, we may write

$$
\frac{F v}{2}=\frac{q w v^{2}}{2 g}
$$

and therefore

$$
F=\frac{q w v}{g}
$$

The force $F$ will be exerted against any obstruction in its path and its magnitude will depend on the momentum of the moving stream of water and is directly proportional to its velocity. It is also a function of the angle through which the jet is deflected. 
If friction be ignored, the stream will be diverted without change in velocity and the force exerted in the original direction of the jet will be equal to the momentum of the original stream less the component, in the original direction, of the momentum of the diverted jet. (See Fig. 3.)

$$
F=\frac{q w v}{g}-\frac{q w v^{\prime}}{g} \cos \alpha=\frac{q w v}{g}(1-\cos \alpha)
$$

If the jet is deflected $180 \mathrm{deg}$. by means of a semi-cylindrical bucket, $\cos 180$ deg. $=-1$, and therefore (see Fig. 4)

$$
F=2 \frac{q w v}{g}
$$

Tangential wheels utilize the impulsive force of a jet impinging against buckets attached to their circumference and practically semicircular in section.

The bucket must move under the impulse in order to transform the energy of the impact, and the ratio of $v^{\prime}$, the velocity of the center of the buckets, to the velocity, $v$ Fig. 3-Force of Diverging Jet. of the jet, is indicated by $\phi$.

$$
\phi=\frac{v^{\prime}}{v}
$$

The force $F$ exerted on the moving bucket is dependent on the relative velocity, $v_{r}$, of the bucket and jet.

$$
v_{r}=v-\phi v=(1-\phi) v
$$

The relative weight of water that strikes a single bucket per second will also be less on account of the movement of the buckets. But as new buckets constantly intercept the path of the jet, the total amount of water effective is equal to the total discharge of the jet, hence, from equation (7),

$$
F=(1-\cos \alpha) \frac{q w v}{g}(1-\phi)
$$


The energy $E$ expended on the buckets per second is equal to the force, $F$, times the distance, $\phi v$, through which it acts, i.e.,

$$
E=F \phi v=(1-\cos \alpha)(1-\phi) \frac{q w v}{g} \phi v
$$

This is a maximum when $(1-\phi) \phi$ is a maximum or when $\phi=0.5$. Substituting $\phi=0.5$ and $\cos \alpha=180 \mathrm{deg}$. above, we then obtain

$$
E=\frac{q w v^{2}}{2 g}
$$

In an impulse wheel, it is not practicable to change the direction of the water through $180 \mathrm{deg}$, , as it would then interfere

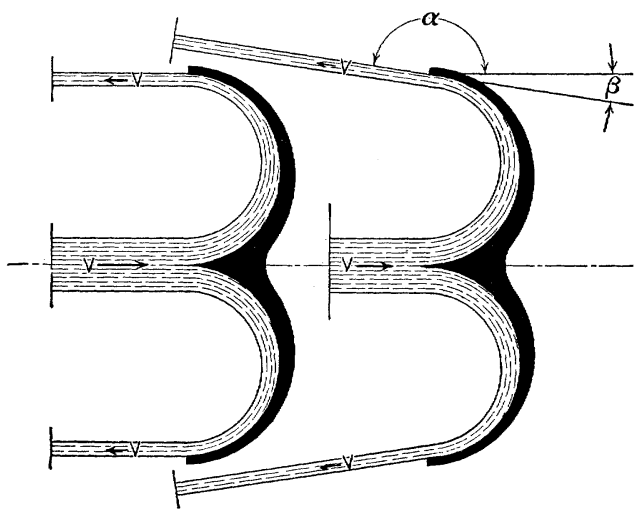

Fig. 4--Jet Diverging 180 Degrees.

with the succeeding bucket. The angle $\cos \alpha$ must therefore be less than 180 deg., but the loss from this source is small, probably not more than 0.5 per cent.

Fig. 5 illustrates graphically the flow of water into and through the bucket of a tangential wheel at the most economical relative velocity. The bucket is double, each half being essentially semicircular in section. $v$ is the absolute velocity of the jet; $v^{\prime}$ is the absolute velocity of the bucket; $v_{r}$ is the relative velocity of the jet in relation to the bucket; or, $v_{r}=(1-\phi) v$. The bucket is moving in the direction $B B^{\prime}$ and occupies successively the positions indicated by the vertical lines $a, a_{1}, a_{2}$, etc., in equal intervals of time. The water moves along the surface of the bucket with a uniform velocity, $v_{r}$, passing successively through 
equal distances, indicated on the surface of the bucket by the lines $b, b_{1}, b_{2}$, etc., in equal intervals of time.

At each of these successive points the jet has changed its direction and its absolute velocity. Its path through space is represented by the line $B C D$. The change in velocity is represented by the absolute velocity curve, $E F$, in which ordinates are the resultants obtained by applying the principle of triangle

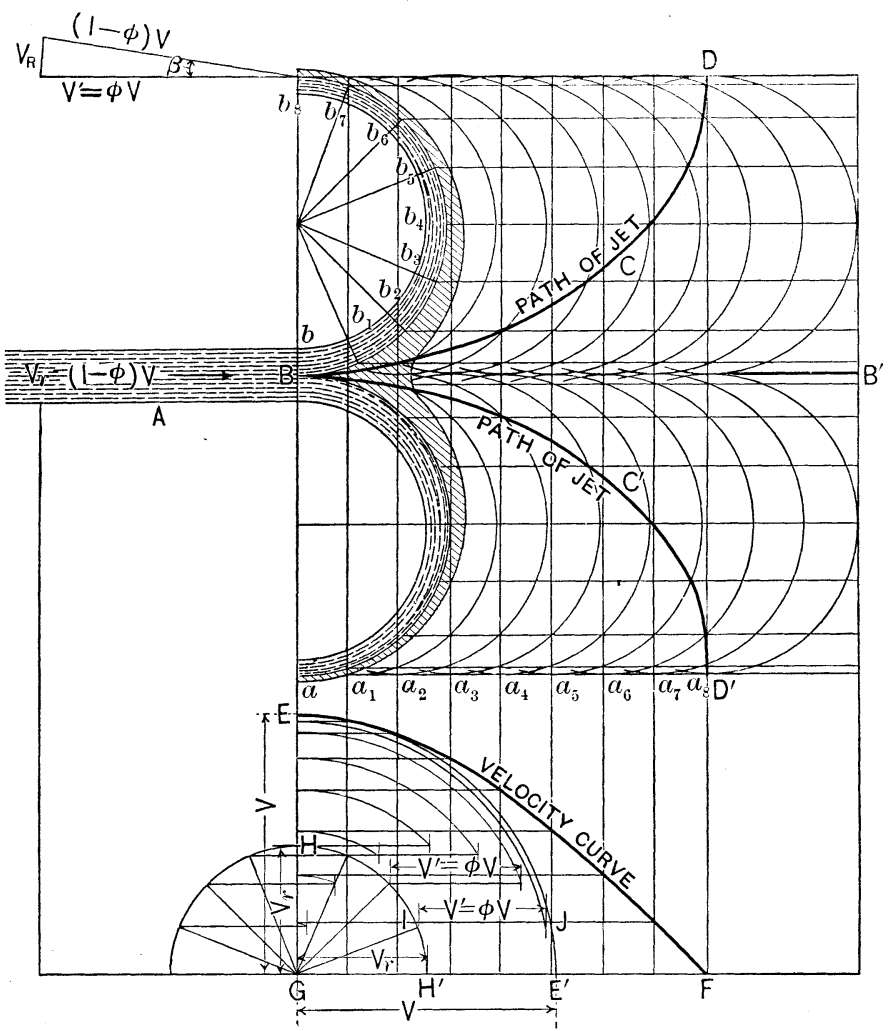

Fig. 5-Graphical Illustration of Flow in Tangential Buckets.

of velocities to corresponding velocities of the bucket and of the water relative to the bucket.

At the time of entering the bucket the stream has the absolute velocity, $v$, represented by the length of the line $G E$ and $G E^{\prime}$, in the lower diagram, while its velocity relative to the bucket is constant and equal to $v_{r}$, equal to the length of lines $G H$ and $G H^{\prime}$. For the most effective speed, $v_{r}=v / 2$. 
At the end of the first interval of time, the jet has moved from the original point of contact with the bucket, $b$, to the position $b_{1}$. Its direction and velocity in the upper half of the bucket are represented by the radius $G I$ in the lower velocity diagram. $v^{\prime}=$ $\phi v$, is constant both in magnitude and direction, and this is laid off in the lower diagram on the line $I J$. The resultant of these two velocities is represented by the line $G J$, which is the absolute velocity of the water in space, and to indicate the velocity of the water at this instant is laid off for the purpose of the velocity diagram on the ordinate $a_{1}$ from the axis $G F$ in the lower diagram. In the same manner each of the remaining points on the velocity curve $E F$ is constructed. The jet leaves the bucket, as shown, with a velocity, relative to the bucket, of $(1-\phi) v$. If this velocity is combined graphically with the velocity of the bucket $\phi v$, the true absolute residual velocity $v_{r}$ of the water will be obtained. The efficiency is evidently maximum when $\phi$ has a value with $v_{r}$ a minimum. This condition can be shown to obtain when the triangle is isosceles or when $\phi_{v}=(1-\phi) v$ which gives $\phi=0.5$.

The hydraulics of the tangential wheel has been discussed somewhat at length on account of its simplicity. If the friction of water and air on the bucket could be obviated, and if the friction of moving power could be eliminated, the runaway speed of the wheel would be equal to the spouting velocity of water, which in turn is slightly less than $\sqrt{2 g h}$ on account of nozzle and atmospheric friction. In practise, therefore, the runaway speed of the tangential wheel is less than $\sqrt{2 g h}$, i.e., $\phi_{\max }$. $<1.00$. In consequence of these friction losses, it was also found in the case of the small experimental tangential wheel that the values of $\phi_{\max }$. vary considerably with different heads under which the experiment was conducted. (See Table I.)

The value of $\phi_{\max }$. apparently increases with the head somewhat to about 73 feet, on account of the relatively large friction loss at the lower heads, and then decreases somewhat to the maximum head, probably on account of the less efficient action of the larger quantities of water discharged from the jet onto the buckets at the higher head. These results should probably vary with the quantity of water for which the bucket is designed. In the tangential wheel the wheel diameter should be measured between the center lines of the bucket, on which lies the center of the application of the resultant of the combined stream lines of the jet. The peripheral velocity 
of the wheel measured on this line of application can never be faster, theoretically, than the spouting velocity of the water, and practically is reduced by friction and windage from 10 to 20 per cent or more below this velocity.

Table II shows the results of various tests which have been made on tangential wheels. In this table are given as determined by experiments, the runaway speed ratio, $\phi_{\max }$, the most efficient speed ratio, $\phi_{e}$, and the values of $\phi$ both higher and lower than $\phi_{e}$ at which the efficiency of the wheel was 5 per cent below the maximum efficiency of the speed $\phi_{e}$. Below each value of $\phi$ the percentage that value bears to $\phi_{\max }$. is given. It should be noted that any cause that reduces efficiency reduces $\phi_{\max }$. as for example, the use of flat buckets in experiment No. 7 .

TABLE I

RUNAWAY SPEED OF 12-IN. DOBLE TANGENTIAL WHEEL AT VARIOUS HEADS

\begin{tabular}{|c|c|c|c|c|}
\hline Head (feet) & Rev. per sec. & $v=\sqrt{2 g h}$ & $v^{\prime}$ & $\phi_{\max .}$ \\
\cline { 1 - 5 } 13.3 & 7.4 & 29.25 & 23.28 & 0.796 \\
25 & 10.14 & 40.1 & 31.62 & 0.79 \\
36.6 & 12.63 & 48.52 & 39.8 & 0.82 \\
49.4 & 14.77 & 56.37 & 46.5 & 0.825 \\
61 & 16.45 & 62.55 & 51.7 & 0.826 \\
72.6 & 17.92 & 67.25 & 56.5 & 0.842 \\
83.9 & 19.45 & 73.4 & 61.4 & 0.838 \\
95.3 & 20.81 & 78.3 & 65.5 & 0.837 \\
108.3 & 22.05 & 83.5 & 69.4 & 0.832 \\
118.7 & 23.05 & 87.5 & 72.5 & 0.829 \\
130.1 & 24.25 & 91.5 & 76.4 & 0.835 \\
141.9 & 25.4 & 95.5 & 80 & 0.8385 \\
153.5 & 25.61 & 99.5 & 80.6 & 0.811 \\
165.1 & 26.59 & 106 & 83.5 & 0.787 \\
\hline
\end{tabular}

It is evident that the diameter of the wheel may be measured on some other circumference than that on which the center of the jet is applied. If, for example, a rim or extension were added to the wheel beyond the bucket, or if the buckets themselves extended considerably beyond the center of pressure, and if the diameter and peripheral velocity of the wheel is measured at any such exterior circumference beyond the line of application of the jet, the peripheral velocity so measured will be found to be materially greater than if measured at the bucket centers. The peripheral velocity so increased may be so great that the resulting value of $\phi_{\max }$. will equal or exceed the spouting velocity of water or 1 . In reaction wheels such conditions actually obtain. 





The curves of the reaction bucket are so complicated that the center of application of the resultant pressures cannot be accurately determined. The diameters of reaction wheels are therefore measured on the outer diameter of the buckets and consequently outside of the center of application of forces, as above discussed. The result is that the value of $\phi_{\max }$ in the reaction wheels is greater than unity.

The relative values of $\phi_{m a x}$. in the various types of reaction wheels are further complicated by the fact that the outer diameter of the runner may vary at different points, and that even when the runners of various makers are of similar design, the same size of wheel may be measured at different points, and consequently, be listed as of different diameter. In general, the section of reaction of wheel may be represented by the two outlines in Fig. 6, and in practise are measured on the various lines marked $D, D^{\prime}, D^{\prime \prime}, D^{\prime \prime \prime}$.

American practise, in the measurement of turbine waterwheel diameters, as far as I have been able to determine, is given in Table III.

\section{Hydraulics of the Reaction Turbine}

The hydraulics of the reaction wheel, on account of a more complicated curvature of the buckets, is apparently more involved. The reaction wheel is, however, subject to essentially the same principles, although their application is somewhat more obscure.

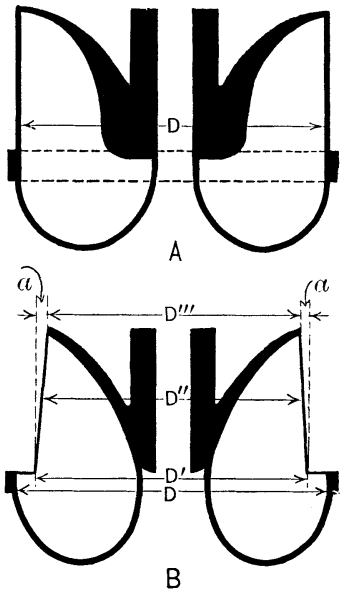

Fig. 6

The velocity of the water through the buckets of the reaction turbine is less than in the tangential wheel, and the energy of the water is delivered through pressure instead of through impact. The energy in both cases is delivered through the reactive pressure, due to a change in the direction of the water jet through contact with the surface of the bucket of the turbine, and in the reaction wheel the conditions are also essentially as shown in Fig. 5.

If the reaction wheel could be measured on the diameter of the circumference at which the resultant of the active jets of water is applied, the resulting velocities would closely approximate those of the tangential wheel. 
On account of the diversity in practise in the measurement of the diameters of reaction turbines, and also on account of the diversity of this design, a general statement of the value of $\phi_{\max }$ cannot be made, for this value varies considerably in the different makes of turbine waterwheels. Reaction wheels vary greatly in design and may be roughly classified as low-speed,

TABLE III

PRACTISE OF VARIOUS AMERICAN MANUFACTURERS IN MEASURING AND CATALOGING THE DIAMETER OF TURBINE WATER WHEELS

\begin{tabular}{|c|c|c|c|}
\hline Manufacturer & Type of runner & Style & Point of measurement \\
\hline \multirow{5}{*}{$\begin{array}{l}\text { A-C } \\
\text { D-G }\end{array}$} & & $B$ & $D^{\prime \prime}$ \\
\hline & A & $A$ & $D$ \\
\hline & $\mathrm{N}-\mathrm{A}$ & $A$ & $D$ \\
\hline & $\mathrm{S}-\mathrm{A}$ & $B$ & $D^{\prime \prime}$ \\
\hline & I-A & $B$ & $D^{\prime}$ \\
\hline \multirow[t]{2}{*}{$\mathrm{R}-\mathrm{H}$} & $\mathrm{Mc}^{2}$ & $B$ & $D$ \\
\hline & $\mathrm{H}$ & $A$ & $D$ \\
\hline \multirow[t]{4}{*}{$J-\mathrm{I}$} & S-L & $A$ & $D$ \\
\hline & $\mathrm{Sp}-\mathrm{L}$ & $A$ & $D$ \\
\hline & $S$ & $B$ & $D$ \\
\hline & I-S & $B$ & $D$ \\
\hline \multirow{3}{*}{$\underset{P-I}{J}$} & $\mathrm{Mc}$ & $B$ & $D^{\prime \prime}$ \\
\hline & Type A & B & $D^{\prime}$ \\
\hline & Types B and C & $A$ & $D$ \\
\hline \multirow[t]{2}{*}{$\mathrm{M}-\mathrm{S}$} & $\mathrm{Mc}^{3}$ & $B$ & $D^{\prime}$ \\
\hline & S & $B$ & $D^{\prime}$ \\
\hline \multirow[t]{2}{*}{$\mathrm{T}$} & $S-T^{4}$ & $B$ & $D^{\prime \prime \prime}$ \\
\hline & $\mathrm{H}-\mathrm{T}$ & $B^{5}$ & $D$ \\
\hline W-S & & $B$ & $D^{\prime \prime}$ \\
\hline
\end{tabular}

1. Fillet at angle. Diameter measured just above.

2. Diameter of runners as measured at the crown which projects beyond the tips of the buckets and is essentially the same in diameter as at $D^{\prime}$.

3. Diameter of the runners as measured at the crown which projects beyond the tips of the buckets and is essentially the same in diameter as at $D^{\prime}$.

4. Diameter at $D$ is 20 per cent greater than at $D^{\prime \prime \prime}$.

5. Bucket of high-speed runner has parallel edges but is cut back as shown in $B$.

moderate-speed, and high-speed wheels. In the low-speed wheels, the values of $\phi_{e}$ which will result in the greatest efficiency will vary perhaps from 0.60 to 0.70 ; for moderate-speed from 0.70 to 0.80 , and for high-speed, from 0.80 to 0.90 . This, however, is a general statement and others might not agree to the exact limits of values given. In each case the actual speed of the wheel under the conditions of operation should be determined and the 
maximum speed which may possibly obtain. When the runaway speed of the waterwheel is definitely known and the value of $\phi_{e}$ at which the waterwheel will operate under fixed head is also established, the relation of the operating to the runaway speed can be definitely determined and the deduction drawn as to the necessary strength of the rotary machinery to be operated thereby. In many cases, however, the head under which the turbine is to operate is not fixed, but varies between conditions of extreme high water and conditions of extreme low water. In low-head plants the head is normally much greater under low water conditions and much less during flood conditions. This variation may in some cases be relatively great. In ordinary practise it is not unusual for the minimum head to be 50 per cent of the maximum head. In such cases, the relative speed of the wheel will vary in its relation to the spouting velocity of water inversely as the square of the head; and in the case mentioned, will vary essentially as 10 is to 7 ; that is to say, where the minimum head is one-half of the maximum and the wheel is operating at a uniform speed, the value of $\phi$ will vary under different conditions, for example, from 0.49 to $0.70,0.56$ to $0.80,0.63$ to 0.90 , or 0.70 to 1 . In many modern turbines, such ranges of relative speed are possible with fairly good resulting efficiency. In such cases, the most satisfactory relative speed and practically the highest efficiency will be reached at a point intermediate between the extremes given. Under such conditions, the relative operating speed of wheels under conditions of high head is much lower than under the best conditions, and under low head is much higher than for the best conditions, and if the turbine should overspeed during periods of high heads, the relative increase in speed due to the runaway condition will greatly exceed that which would obtain under normal conditions or under low head conditions. In order to form a basis for an intelligent estimate of the relation of the runaway speed of wheels to the operating speed under the conditions outlined, I have prepared Table IV, showing the results under test of various types of reaction waterwheels on which experiments have been made. In this table is given the value $\phi_{\max }$ corresponding to the runaway speed as determined by experiment, also the value $\phi_{e}$ at which the maximum efficiency was secured. There is also given the variations in $\phi$ at which the wheels operated with 5 per cent less efficiency both above and below the most economical speed. These variations in $\phi$ correspond approximately to those required for the 50 per cent 
TABLE IV. RELATION OF SPEED RATIOS UNDER OPERATING AND RUNAWAY CONDITIONS

\begin{tabular}{|c|c|c|c|c|c|c|c|}
\hline \multicolumn{8}{|c|}{ Reaction Wheels } \\
\hline \multirow{2}{*}{$\begin{array}{l}\text { Manu- } \\
\text { facturer }\end{array}$} & \multirow{2}{*}{$\begin{array}{l}\text { Hol- } \\
\text { yoke } \\
\text { test } \\
\text { num- } \\
\text { ber }\end{array}$} & \multirow{2}{*}{$\begin{array}{l}\text { Diam. } \\
\text { of } \\
\text { runner }\end{array}$} & \multicolumn{3}{|c|}{$\begin{array}{l}\text { Values of } \phi \\
\text { for relative efficiency }\end{array}$} & \multirow{2}{*}{$\begin{array}{c}\text { Runaway } \\
\text { ratio } \\
\phi_{\max }\end{array}$} & \multirow[t]{2}{*}{ Remarks } \\
\hline & & & $-5 \%$ & $\phi_{e}$ & $-5 \%$ & & \\
\hline W-S & 1795 & $32 \mathrm{in.}$ & $\begin{array}{l}0.563 \\
218 \%\end{array}$ & $\begin{array}{l}0.738 \\
153 \%\end{array}$ & $\begin{array}{c}0.826 \\
148.4 \%\end{array}$ & 1. 225 & Feb., 1909 \\
\hline W-S & 1796 & 28 in. & $\begin{array}{l}0.675 \\
180 \%\end{array}$ & $\begin{array}{l}0.800 \\
151.9 \%\end{array}$ & $\begin{array}{l}0.965 \\
126 \%\end{array}$ & 1.215 & Feb., 1909 \\
\hline $\mathrm{W}-\mathrm{S}$ & 1797 & $30 \mathrm{in.}$ & $\begin{array}{c}0.681 \\
181.6 \%\end{array}$ & $\begin{array}{c}0.782 \\
158.1 \%\end{array}$ & $\begin{array}{c}0.961 \\
128.7 \%\end{array}$ & 1.238 & Feb., 1909 \\
\hline $\mathrm{W}-\mathrm{S}$ & 1799 & 31 in. & $\begin{array}{c}0.640 \\
190.4 \%\end{array}$ & $\begin{array}{c}0.755 \\
161.2 \%\end{array}$ & $\begin{array}{c}0.874 \\
139.4 \%\end{array}$ & 1.218 & March 1909 \\
\hline $\mathrm{W}-\mathrm{S}$ & 1800 & 31 in. & $\begin{array}{c}0.669 \\
192.2 \%\end{array}$ & $\begin{array}{c}0.781 \\
164.5 \%\end{array}$ & $\begin{array}{c}0.943 \\
136.2 \%\end{array}$ & 1.285 & March, 1909 \\
\hline$A-C$ & 1778 & 30 in. & $\begin{array}{c}0.668 \\
203.2 \%\end{array}$ & $\begin{array}{c}0.815 \\
166.6 \%\end{array}$ & $\begin{array}{l}1.012 \\
134 \%\end{array}$ & 1.358 & \\
\hline$A-C$ & 1883 & $30 \mathrm{in.}$ & $\begin{array}{c}0.613 \\
217.5 \%\end{array}$ & $\begin{array}{c}0.75 \\
177.5 \%\end{array}$ & $\begin{array}{c}0.896 \\
148.6 \%\end{array}$ & 1.332 & \\
\hline$A-C$ & 1815 & $45 \mathrm{in.}$ & $\begin{array}{c}0.691 \\
183.8 \%\end{array}$ & $\begin{array}{c}0.815 \\
155.8 \%\end{array}$ & $\begin{array}{c}0.987 \\
128.6 \%\end{array}$ & $1.270 \dagger$ & to. 9 gate \\
\hline M-S & 1983 & $30 \mathrm{in.}$ & $\begin{array}{c}0.629 \\
188.9 \%\end{array}$ & $\begin{array}{c}0.767 \\
155 \%\end{array}$ & $\begin{array}{c}0.848 \\
140 \%\end{array}$ & 1.188 & Feb., 1911 \\
\hline $\mathrm{M}-\mathrm{S}$ & 1820 & 48 in. & $\begin{array}{c}0.631 \\
194 \%\end{array}$ & $\begin{array}{c}0.75^{\prime \prime} \\
162 \%\end{array}$ & $\begin{array}{c}0.930 \\
131.5 \%\end{array}$ & 1.224 & June 1909 \\
\hline$J-L$ & 1690 & $\begin{array}{l}45 \text { in. } \\
\left(38 \frac{1}{2} \text { in. }\right) *\end{array}$ & & & & $\begin{array}{l}1.412 \\
(1.21) \dagger\end{array}$ & Sept., 1907 \\
\hline$J-L$ & 1903 & $\begin{array}{l}50 \text { in. } \\
\left(43 \frac{1}{2} \text { in. }\right)^{*}\end{array}$ & & $\begin{array}{c}0.868 \\
157.2 \%\end{array}$ & & $\begin{array}{c}1.365 \\
(1.19) \dagger\end{array}$ & \\
\hline J-L & 1896 & $\begin{array}{l}35 \text { in. } \\
\left(30 \frac{1}{2} \text { in. }\right)^{*}\end{array}$ & & $\begin{array}{l}0.899 \\
156 \%\end{array}$ & & $\begin{array}{l}1.40 \\
(1.22) \dagger\end{array}$ & April, 1910 \\
\hline D-G & 1509 & 44 in. & $\begin{array}{c}0.652 \\
192 \%\end{array}$ & $\begin{array}{l}0.781 \\
160 \%\end{array}$ & $\begin{array}{c}0.932 \\
134.1 \%\end{array}$ & 1.250 & March, 1904 \\
\hline $\mathrm{D}-\mathrm{G}$ & 1835 & $60 \mathrm{in.}$ & $\begin{array}{c}0.639 \\
198 \%\end{array}$ & $\begin{array}{c}0.759 \\
166.4 \%\end{array}$ & $\begin{array}{c}0.937 \\
134.9 \%\end{array}$ & 1.263 & Aug., 1909 \\
\hline $\begin{array}{c}\text { J. B. Francis } \\
\text { Fourneyron } \\
\text { turbine }\end{array}$ & & 113 in. & $\begin{array}{r}0.44 \\
356 \%\end{array}$ & $\begin{array}{r}0.75 \\
209 \%\end{array}$ & $\begin{array}{l}0.101 \\
155 \%\end{array}$ & 1.566 & $\begin{array}{r}\text { See Water } \\
\text { Power Engi- } \\
\text { neering p. 703 }\end{array}$ \\
\hline $\mathrm{R}$ & & $48 \mathrm{in.}$ & $\begin{array}{r}0.54 \\
190 \%\end{array}$ & $\begin{array}{c}0.68 \\
150.5 \%\end{array}$ & $\begin{array}{l}0.79 \\
129.5 \%\end{array}$ & 1.023 & $\mid \begin{array}{cc}\text { See } & \text { Water } \\
\text { Power } & \text { Engi- } \\
\text { neering, } & \text { p.704 }\end{array}$ \\
\hline $\mathrm{H}-\mathrm{M}$ & 988 & $42 \mathrm{in.}$ & & $\begin{array}{r}66.5 \\
168 \%\end{array}$ & & 1.120 & $\begin{array}{c}\text { See Water } \\
\text { Supply and } \\
\text { Irrigation } \\
\text { paperU.S.G.S } \\
\text { No. } 180 \text { p.60. }\end{array}$ \\
\hline $\mathrm{H}-\mathrm{M}$ & 1030 & $45 \mathrm{in.}$ & & $\begin{array}{r}66.5 \\
169 \%\end{array}$ & & 1.124 & $\begin{array}{l}\text { See Water } \\
\text { Supply and } \\
\text { Irrigation } \\
\text { paper U. S. } \\
\text { G.S., No.180 } \\
\text { page 60 }\end{array}$ \\
\hline $\mathrm{H}-\mathrm{M}$ & 1077 & $51 \mathrm{in.}$ & & $\begin{array}{l}67.7 \\
170 \%\end{array}$ & & 1.151 & $\begin{array}{l}\text { See Water } \\
\text { Supply and } \\
\text { Irrigation } \\
\text { paper U. S. } \\
\text { G.S., No.180 } \\
\text { page } 64\end{array}$ \\
\hline
\end{tabular}

Note. Percentages show relations of runaway to operating speeds.

*These diameters show the corresponding size of the wheel measured at the center of the gates and values of $\phi_{\text {max }}$. marked $\dagger$ show the values calculated on the se diameters.

$¥$ †o longer manufactured. 
range in heads discussed above. In each case the percentage of $\phi_{\max }$ to the operating value of $\phi$ is given just below the value in question. This percentage, in both Tables II and IV, shows the relative speed for which attached machinery must be designed to meet runaway conditions if operated at $\phi_{e}$ or under the two extremes given.

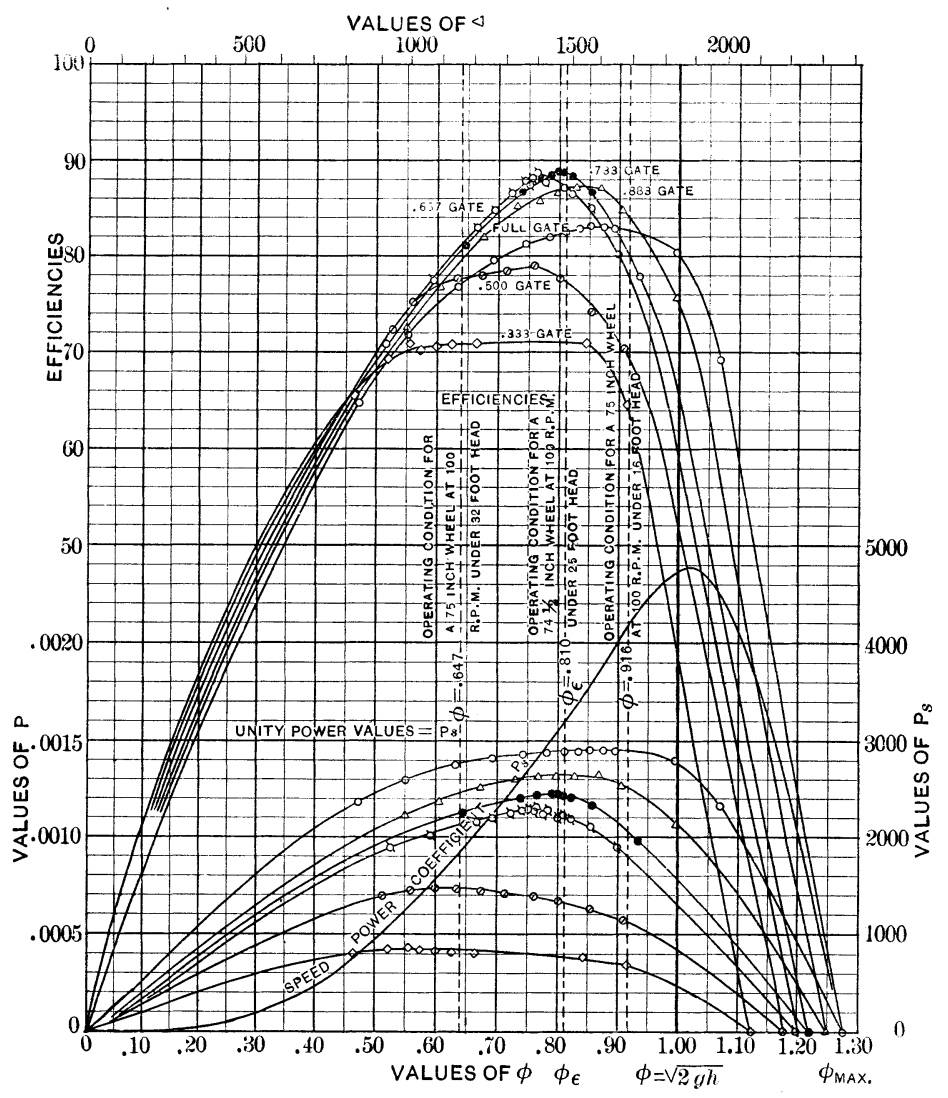

Fig. 7

For the J-L wheels the values of $\phi$ are calculated both for the table diameter and also for the actual diameter measured at the center of the gates. From a comparison of these values it will be noted that while the speed of these wheels seems unduly high when based on the maker's measurements they actually correspond closely with other standard wheels when based on the diameter measured at the gate centers. 
From Tables II and IV some general conclusions can be drawn, but as in most problems of this class, general statements are apt to be misleading, and the speed problem should be carefully analyzed for each particular case.

As a brief example of such wheel analysis, the writer has considered a single type of wheel under various conditions of use. Fig. 7 shows a complete graphical record of the $\mathrm{W}-\mathrm{M}$ test (No. 1800) of a 31-in. reaction turbine, so analyzed that all of the fundamental data for power, speed and efficiency are given for any wheel of homologous design, or identical in type, regardless of size, as well as for the particular wheel on which the experiments were made.

In this diagram are given the values of:

The efficiency of such wheels at various relative speeds.

$\phi=$ the ratio of peripheral to spouting velocity.

$\Delta=$ the speed at one-foot head of a one-inch wheel of homologous design.

$P=$ the power under one-foot head, of a one-inch wheel of homologous design.

$\rho_{s}=$ the speed-power coefficient.

The value of $P_{s}$ is expressed by the equation

$$
P_{s}=\frac{n^{2} P}{h^{5 / 2}}
$$

This coefficient is the square of the coefficient of " unity speed" of the type of wheels considered, and is used in the above form to facilitate calculation for water power purposes.

It should here be noted that in general, when the coefficients of a series of wheels of homologous design are given, they are given for the condition of maximum efficiency, and maximum efficiency can only be obtained by operation under the fixed value of $\phi_{e}$ or $\triangle_{e}$.

Any wheel, however, may be so installed or operated that $\phi$ or $\triangle$ may vary from 0 to maximums which are approximately

$$
\begin{aligned}
\phi_{\max } & =1.28 \\
\triangle_{\max } & =2400
\end{aligned}
$$

In consequence $\odot$ will vary from 0 with $\phi=0$ to an approximate maximum with $\phi_{e}$ and then to 0 again with $\phi_{\max }$.

Efficiency will vary in essentially the same manner. 
As $\mathcal{P}_{s}$ varies with the square of the speed and directly with the power at full gate, it also varies from 0 with $\phi=0$ through a maximum to a value of 0 at $\phi_{\max }$. The maximum value of $\mathcal{P}_{s}$ does not occur with $\phi_{e}$, as will be noted from Fig. 7 .

In many series of wheels of homologous design the following principles hold within the limits of error due to imperfect design, construction and installation.

Where $\phi$ is held at a constant value:

Efficiency will remain constant for any given gate opening

$$
\frac{D n}{\sqrt{h}}=\frac{D_{a} n_{a}}{\sqrt{h_{1}}}
$$

i.e., the rev. per min. vary directly with $\sqrt{ } \bar{h}$ and inversely with the diameter of the wheel.

$$
\frac{P}{D^{2} h^{3 / 2}}=\frac{P_{a}^{*}}{D_{a}^{2} h_{a}^{3 / 2}}
$$

i.e., the power of wheels varies directly with $D^{2}$ and with $h^{3 / 2}$.

With wheels of the same diameter and with $\phi$ held at a constant value

$$
\frac{n}{\sqrt{h}}=\frac{n_{a}}{\sqrt{h_{a}}}
$$

The rev. per min. of a wheel vary directly with $\sqrt{h}$.

$$
\frac{P}{h^{3 / 2}}=\frac{P_{a}}{h_{a}^{3 / 2}}
$$

The power of a wheel varies directly with $h^{3 / 2}$

The following relations also obtain:

$$
\begin{gathered}
\phi=\frac{v^{\prime}}{v}=\frac{\triangle}{1842}=\frac{D n}{1842 \sqrt{h}} \\
P=\odot D^{3 / 2} \\
P=\frac{P_{s} h^{5 / 2}}{n^{2}}
\end{gathered}
$$

Referring to Fig. 7, it is evident that the maximum efficiency may be obtained from this series of wheels when $\phi_{e}=0.81$ and $\rho_{\text {s }}=3200$. 
If we desire to secure 1000 h.p. with a wheel of this type at 25 -foot head and 100 rev. per min.,

$$
\begin{aligned}
& n_{1}=\text { speed at one-foot head }=\frac{n}{\sqrt{h}}=\frac{100}{\sqrt{25}}=20 . \\
& P_{1}=\text { power at one-foot head }=\frac{P}{h^{3 / 2}}=\frac{1000}{125}=8 . \\
& P_{s}=n_{1}^{2} P_{1}=3200 .
\end{aligned}
$$

This shows that a wheel of this series will operate under these conditions to the best advantage.

The size of the wheel can then be determined as follows:

$$
\begin{aligned}
D & =\frac{1842 \phi}{n_{1}}=74.5 \text { inches }=\text { diameter of wheel. } \\
\frac{\phi_{\max } .}{\phi_{e}} & =\frac{1.275}{0.81}=157 \text { per cent }=\text { relative runaway speed. }
\end{aligned}
$$

Runaway speed $=157$ revolutions per minute.

If we desire to operate a wheel of this type and of 75 -in. diameter under conditions where the head will vary from 16 to $32 \mathrm{ft}$. under various conditions of river flow, a somewhat different problem must be considered. With $\phi_{e}=0.81$ and $h=32$, a 75 -in. wheel would run at 113 rev. per min. and would give 1470 h.p. at full gate.

With $\phi=0.81$ and $h=16$, a 75 -in. wheel should run at 80 rev. per min. and give 520 h.p. In order to run at both heads with reasonable satisfaction a constant and intermediate speed must be selected, which from trial appears to be $n=90$.

Under this condition

$$
\begin{aligned}
& \text { with } h=16, \phi=\frac{75 \times 90}{1842 \times 4}=0.916 ; \odot_{s}=4100 ; P=520 . \\
& \text { with } h=32, \phi=\frac{75 \times 90}{1842 \times 5.6}=0.647 ; \odot_{\diamond}=1900 ; P=1270 .
\end{aligned}
$$

Under these conditions the power and efficiency is considerably reduced at $32-\mathrm{ft}$. head, which may, however, be warranted by the condition.

Under the above conditions the runaway speed at the $32 \mathrm{ft}$.head will be

$$
\frac{\phi_{\max .}}{\phi}=\frac{1.275}{0.647}=197 \text { per cent }=177 \mathrm{rev} . \text { per } \min .
$$


In this manner the actual runaway speed can be ascertained with any given wheel and under any condition of head. It should be noted, however, that the results may be modified somewhat by various physical conditions.

1. The value of $\phi_{\max }$ under high heads may increase somewhat over that determined by tests given above, on account of the fact that the friction does not increase as rapidly as the power under increased heads.

2 . The value of $\phi_{\max }$ will decrease slightly when the turbines are directly connected to generators on account of the power necessary to move the same when running light.

The writer can offer no data on which to estimate these changes in $\phi_{\max .}$, but such changes are not large.

\section{Conclusions}

From an inspection of Table II it will be seen that in the case of impulse or tangential wheels which are used under high heads, which heads are generally relatively constant, the over-speed to be cared for should be estimated at 100 per cent of the normal speed.

In general, from an inspection of Table IV, it may be stated that when a reaction turbine is working at the most efficient speed ratio $\left(\phi_{e}\right)$ and the head is constant, the runaway speed $\left(\phi_{\max }\right)$ may be as low as 150 per cent or as high as 180 per cent of such speed, according to the type of wheel used, or, otherwise, that the over-speed may be from 50 to 80 per cent above the normal speed of a reaction wheel. If, however, under the low head condition there is wide variation in the head available under different conditions of stream flow, and if the wheel is designed to work under these various conditions, and the speed chosen is intermediate to that which would be chosen under either extreme, then, under the maximum head a runaway speed of 200 per cent or more of the normal speed may be realized.

These conclusions are only general, and in all cases a detailed analysis should be made, based on test data for the particular type of wheel which is to be used, and considered for the extreme range of heads and the exact conditions which must be anticipated. 